\title{
Antisocial behavior from a developmental psychopathology perspective
}

\author{
PAUL J. FRICK ${ }^{a}$ AND ESSI VIDING ${ }^{b}$ \\ ${ }^{a}$ University of New Orleans; and ${ }^{b}$ University College London
}

\begin{abstract}
This paper reviews research on chronic patterns of antisocial behavior and places this research into a developmental psychopathology framework. Specifically, research suggests that there are at least three important pathways through which children and adolescents can develop severe antisocial behaviors. One group of youth shows antisocial behavior that begins in adolescence, and two groups show antisocial behavior that begins in childhood but differ on the presence or absence of callous-unemotional traits. In outlining these distinct pathways to antisocial behavior, we have tried to illustrate some key concepts from developmental psychopathology such as equifinality and multifinality, the importance of understanding the interface between normal and abnormal development, and the importance of using multiple levels of analyses to advance causal theories. Finally, we discuss how this development model can be used to enhance existing interventions for antisocial individuals.
\end{abstract}

The study of antisocial, criminal, and aggressive behaviors has a long and rich research history (Binder, 1987). This intensive focus from research is not surprising given that these behaviors often operate at a very high cost to society, such as costs to victims of these behaviors and the costs associated with detaining individuals in an effort to protect potential future victims (Krug, Dahlberg, Mercy, Zwi, \& Lozano, 2002; Loeber \& Farrington, 2001). Of importance, these behaviors have been studied from a number of different perspectives, including anthropological, evolutionary, sociological, psychological, and biological perspectives, to name a few. Research from each of these disciplines provides a unique perspective for understanding the course, causes, and most effective interventions for individuals who show severe antisocial behaviors. In this paper, and in fitting with this special section, we take a developmental psychopathology ap-

Address correspondence and reprint requests to: Paul J. Frick, Department of Psychology, University of New Orleans, 2001 Geology and Psychology Building, New Orleans, LA 70148; E-mail: pfrick@uno.edu. proach for integrating the large and diverse research literature on antisocial behavior, used broadly to refer to criminal and aggressive behaviors, as well as other behaviors that violate the rights of others or major societal norms.

We think that a developmental psychopathology approach for integrating this research could be important for at least two reasons. First, a developmental psychopathology framework provides a very useful way for integrating the diverse research literatures into a coherent causal model. This can help us to understand the developmental mechanisms that can lead to antisocial behavior patterns and to translate this research into implications for prevention and treatment. Second, research on antisocial behavior provides a clear way of illustrating the importance of several key developmental psychopathology concepts, such as equifinality and multifinality, the importance of integrating research on both normal and abnormal development, and the importance of integrating multiple level of analyses (e.g., neurological, social, cognitive, behavioral) for understanding psychopathological conditions.

One broad question that is often raised in taking a developmental psychopathology perspective on antisocial behavior is whether or 
not patterns of antisocial behavior should or should not be considered a psychopathological condition, psychiatric disorder, or mental illness (Richters \& Cicchetti, 1993; Wakefield, Pottick, \& Kirk, 2002). We think that a developmental psychopathology perspective cannot completely address this question because the answer is largely dependent on how one defines “mental disorder" (Lilienfeld, \& Marino, 1995; Wakefield, 1992). This is, if a mental disorder is defined solely as a pattern of behavior that causes harm for a person (e.g., leads to or puts him or her at risk for impairments in psychological, social, or occupational functioning or for violating the rights of others), then impairing levels of antisocial behavior would fit well within such a definition of a disorder. In contrast, other definitions, such as those that require the disruption of some internal mechanism in the person (e.g., Wakefield, 1992), may fit for some antisocial individuals but not others. A developmental psychopathological perspective can help to define the various different causal pathways that may lead to antisocial behavior, some of which fit particular definitions of mental disorders and others that do not. Further, this perspective can uncover factors (e.g., biological, social) that can disrupt a person's normal development and lead to the problematic behavior, again defining some patterns that may fit with certain definitions of mental disorders and others that do not. Thus, the developmental psychopathology perspective can provide a way of conceptualizing antisocial behavior and its causes that informs the debate regarding criteria for a disorder, but it cannot determine the "best" method for differentiating disordered and nondisordered individuals. This issue is largely dependent on the purpose for making this distinction.

Another broad classification issue relates to the great diversity of behaviors subsumed under the rubric of antisocial behavior (Frick et al., 1993). This large and heterogeneous set of behaviors has led to numerous attempts to define meaningful subtypes of antisocial youth based on the particular pattern of behaviors they exhibit (for a review, see Frick \& Marsee, 2006). Some examples include the distinction made in the Diagnostic and Statistical Manual of Mental Disorders-Fourth Edition, Text Revi- sion (DSM-IV-TR; American Psychiatric Association, 2000) between argumentative, noncompliant, and oppositional behaviors subsumed under the diagnosis of oppositional defiant disorder and the aggressive, destructive, deceitful, and norm-violating behaviors of conduct disorder. Other distinctions have been made between overt conduct problems involving direct confrontation (e.g., arguing, fighting, stealing with confrontation) and covert conduct problems that do not involve confrontation (e.g., lying, stealing without confrontation; Snyder et al., 2008) or between aggressive behavior that is reactive (e.g., in response to real or perceived provocation) or proactive (e.g., premeditated or for instrumental gain) in nature (Card \& Little, 2006; Marsee \& Frick, 2007). Still other methods classify youth based on the trajectory of their antisocial behavior over time, such as whether the behavior is high and stable, low and stable, high and declining, or low and increasing (Broidy et al., 2003; LaCourse, Depere, \& Loeber, 2008).

A further classification concern, and one that is particularly relevant to the focus of this special issue, is the relationship between antisocial behavior patterns and personality disorders. For some classification systems, including the most recent versions of the DSM (American Psychiatric Association, 1980, 1987, 2000), chronic patterns of severe antisocial behavior and antisocial personality disorder are considered synonymous concepts (Robins, 1978). However, there have been several alternative approaches to classifying antisocial individuals that focus on the personality traits that may underlie the chronic antisocial behavior. For example, individuals with chronic patterns of antisocial behavior can be classified based on their pattern of scores on the Big Five personality dimensions. Specifically, antisocial individuals often are low on the personality dimensions of agreeableness and conscientiousness (Lynam \& Widiger, 2001). Another example of this approach using personality features focuses on the affective (e.g., lack of empathy and guilt) and interpersonal (e.g., callous use of others and narcissism) characteristics that have been hallmarks of the construct of psychopathy (Cleckley, 1976; Hare, 1993; Lykken, 1995). This research has indicated that not all individuals who show chronic antisocial and criminal behavior show 
elevated levels of psychopathic traits. In fact, it is only a minority of antisocial individuals who do so. However, the subgroup of antisocial individuals with psychopathic traits show a particularly severe and violent pattern of behavior (Hemphill, 2007; Leistico, Salekin, DeCoster, \& Rogers 2008; Porter \& Woodworth, 2006) and distinct cognitive and emotional deficits compared with other antisocial individuals (Blair, Mitchell, \& Blair, 2005; Patrick, 2007).

A common theme of all of these issues involved in the classification of antisocial individuals is the recognition that there are important subgroups of antisocial individuals that need to be defined by any classification system. Further, most of the approaches that have been used to define more homogeneous subgroups of antisocial individuals have relied on differences in the behavioral manifestations (e.g., type of behavior, trajectory of behavior over time) or differences in personality traits (e.g., Big Five dimensions; presence of psychopathic traits) to make distinctions within antisocial youth. We would argue that a developmental psychopathology approach should emphasize potential differences in the developmental mechanisms that may underlie these behavioral manifestations or personality features. The reason for this emphasis is that sometimes different behavioral manifestations may reflect different development processes underlying the behavior. However, it is also possible that the same behavioral pattern (e.g., high and stable levels of antisocial behavior) can come about through very different developmental mechanisms. Thus, in the following sections, we outline a model for understanding patterns of severe antisocial behavior that focuses largely on the developmental processes that can explain some of the differences in the behavioral manifestations or associated personality traits displayed by antisocial individuals.

\section{The Concepts of Equifinality and Multifinality and Subgroups of Antisocial Youth}

\section{The childhood-versus adolescent-onset distinction}

A number of reviews of the literature have summarized research supporting the distinction between children who begin showing severe conduct problems and antisocial behavior in childhood versus those whose onset of antisocial behavior does not emerge until adolescence (Moffitt, 1993, 2003; Patterson, 1996). Children in the childhood-onset group often begin showing mild conduct problems as early as preschool or early elementary school, and their behavioral problems tend to increase in rate and severity throughout childhood and into adolescence (Lahey \& Loeber, 1994). In contrast, the adolescent-onset group does not show significant behavioral problems in childhood, but they begin exhibiting significant antisocial and delinquent behavior coinciding with the onset of adolescence (Moffitt, 2003). In addition to the different patterns of onset, the childhood-onset group is more likely to show aggressive behaviors in childhood and adolescence, and is more likely to continue to show antisocial and criminal behavior into adulthood (for a review, see Frick \& Loney, 1999).

For example, Farrington, Gallagher, Morley, St. Ledger, and West (1988) reported that boys who were arrested prior to age 12 showed almost twice as many convictions at two later points in time (between the ages of 16 and 18 and between the ages of 22 and 24). Similarly, Robins (1966) reported that boys referred to a mental health clinic for antisocial behavior prior to age 11 were twice as likely to receive a diagnosis of an antisocial personality disorder as an adult, compared to boys who began showing antisocial behavior after age 11. As a final example, Moffitt, Caspi, Harrington, and Milne (2002) reported that, within a birth cohort of 539 males born in New Zealand and followed through age 26 , the 45 men who had displayed significant conduct problems prior to adolescence were more likely to have had a criminal conviction $(55 \%)$ and to have a greater number of convictions $(M=6.9, S D=11.5)$ as adults than the 121 men who showed significant conduct problems starting in adolescence (34\%; $M=3.5, S D=10.8)$. Both groups, however, differed from controls without histories of conduct problems $(17 \% ; M=0.6, S D=3.1)$. The difference was more dramatic when the focus was on convictions for violent offenses, with the early-onset group being much more likely (38\%) to be convicted as an adult than either 
the adolescent-onset (14\%) or control (5\%) groups.

Thus, the childhood and adolescent subtypes of antisocial youth show very different trajectories of antisocial behavior, both in terms of their patterns of onset and life-course trajectory. However, if these were the only differences between groups, this method for subtyping would not be much different from other approaches that have focused on the different behavioral trajectories of antisocial behavior over time. Of importance, there is now a rather extensive body of research to suggest that the two groups also differ on a number of dispositional and contextual risk factors that seem to implicate different developmental processes in the disruptive behaviors of the two groups (Moffitt, 2002). To summarize these findings, childhood-onset conduct problems seem to be more strongly related to neuropsychological (e.g., deficits in executive functioning) and cognitive (e.g., low intelligence) deficits (Fergusson, Lynsky, \& Horwood, 1996; Kratzer \& Hodgins, 1999; Piquero, 2001; Raine, Yaralian, Reynolds, Venables, \& Mednick, 2002). Further, the childhood-onset group has been reported to show more temperamental and personality risk factors, such as impulsivity (McCabe, Hough, Wood, \& Yeh, 2001; Silverthorn, Frick, \& Reynolds, 2001), attention deficits (Fergusson et al., 1996), and problems in emotional regulation (Moffitt, Caspi, Dickson, Silva, \& Stanton, 1996). This group has also been shown to come from homes with greater family instability, more family conflict, and with parents who use less effective parenting strategies (Aguilar, Sroufe, Egeland, \& Carlson, 2000; McCabe et al., 2001; Patterson \& Yoerger, 1997; Woodward, Fergusson, \& Horwood, 2002). When children within the adolescent-onset group differ from control children without conduct problems, it is often in showing higher levels of rebelliousness and being more rejecting of conventional values (Dandreaux \& Frick, 2009; Moffitt et al., 1996).

The different outcomes and risk factors for the two subtypes of antisocial individuals have led to theoretical models that propose very different causal mechanisms operating across the two groups. For example, Moffitt (2003) has proposed that children in the childhood- onset group develop their problem behavior through a transactional process involving a difficult and vulnerable child (e.g., impulsive, with verbal deficits) who experiences an inadequate rearing environment (e.g., poor parental supervision, poor quality schools). This dysfunctional transactional process disrupts the child's socialization leading to poor social relations with persons both inside (e.g., parents and siblings) and outside the family (e.g., peers and teachers). These disruptions lead to enduring vulnerabilities that can negatively affect the child's psychosocial adjustment across multiple developmental stages.

In contrast, children in the adolescent-onset pathway have problems that are more likely to be limited to adolescence and show fewer risk factors. Thus, this group is conceptualized as showing an exaggeration of the normative process of adolescent rebellion (Moffitt, 2003). That is, all adolescents show some level of rebelliousness to parents and other authority figures (Brezina \& Piquero, 2007). This rebelliousness is part of a process by which the adolescent begins to develop his or her autonomous sense of self and his or her unique identity. According to Moffitt (2003), the child in the adolescent-onset group engages in antisocial and delinquent behaviors as a misguided attempt to obtain a subjective sense of maturity and adult status in a way that is maladaptive (e.g., breaking societal norms) but encouraged by an antisocial peer group. Given that their behavior is viewed as an exaggeration of a process specific to adolescence, and not because of an enduring vulnerability, their antisocial behavior is less likely to persist beyond adolescence. However, they may still have impairments that persist into adulthood because of the consequences of their adolescent antisocial behavior (e.g., a criminal record, dropping out of school, substance abuse; Moffitt \& Caspi, 2001).

\section{Callous-unemotional (CU) traits and subgroups of antisocial youth}

This distinction between the childhood and adolescent-onset patterns of antisocial behaviors illustrates a subgrouping approach for antisocial individuals that proposes different developmental mechanisms underlying the problem 
behavior across groups. Thus, this is an example of the important concept in developmental psychopathology of equifinality, which proposes that the same developmental outcome (e.g., antisocial behavior) can result from very different developmental processes (Cicchetti \& Rogosch, 1996). It is important that research has begun extending the concept of equifinality for understanding antisocial youth by exploring whether additional distinctions can be made within groups who show a childhood onset to their antisocial behavior.

This distinction is based on the presence of a callous and unemotional interpersonal style characterized by a lack of guilt and empathy and a callous use of others. It is similar to the distinction made within samples of antisocial adults using the construct of psychopathy that was described previously. As noted previously, within incarcerated adults, the presence of psychopathic traits has proven to designate an important subgroup of antisocial individual who show a more severe, violent, and difficult to treat pattern of antisocial behavior (Hemphill, 2007; Leistico et al., 2008; Porter \& Woodworth, 2006). They also show a number of different background and emotional characteristics that seem to suggest a unique etiology to their antisocial behavior (Blair et al., 2005; Patrick, 2007). There is growing evidence that the same may be true for antisocial youth who show CU traits.

Specifically, youth who show the childhood onset to their antisocial behavior tend to score higher on measures of $\mathrm{CU}$ traits than those who show an adolescent onset (Dandreaux \& Frick, 2009; Moffitt et al., 1996; Silverthorn et al., 2001). Further, several recent qualitative (Frick \& Dickens, 2006; Frick \& White, 2008) and quantitative (Edens, Campbell, \& Weir, 2007; Leistico et al., 2008) reviews have been published showing that $\mathrm{CU}$ traits are predictive of a more severe, stable, and aggressive pattern of behavior in antisocial youth. For example, Edens et al. (2007) conducted a quantitative meta-analyses of 21 nonoverlapping samples showing that measures that include $\mathrm{CU}$ traits were associated with general or violent recidivism with effect sizes of $r=.24$ or .25 , respectively. Frick and Dickens (2006) reported on a qualitative review of 24 published studies using 22 in- dependent samples. Ten of these studies showed a concurrent association between CU traits and measures of aggressive, antisocial, or delinquent behavior and 14 studies showed a predictive relationship with follow-up intervals ranging from 6 months to 10 years. These authors further reported on 5 studies showing that $\mathrm{CU}$ traits were associated with poorer treatment outcomes. Of importance, these studies included community $(n=6)$, clinic-referred $(n=4)$, and forensic $(n=$ 13) samples, and they included samples ranging in age from 4 to 20.

One important issue in interpreting this body of research is that CU traits seem to predict later antisocial behavior even after controlling for other risk factors (e.g., past criminal offenses, drug use, delinquent peers; Salekin, 2008). Further, the association between $\mathrm{CU}$ traits and aggressive behavior could explain some of the typologies proposed for understanding aggressive individuals. That is, youth with $\mathrm{CU}$ traits not only show a more severe and pervasive pattern of aggressive behavior but they also tend to show aggression that is both reactive and proactive in nature (Enebrink, Andershed, \& Langstrom, 2005; Frick, Cornell, Barry, Bodin, \& Dane, 2003; Kruh, Frick, \& Clements, 2005). In contrast, antisocial youth without $\mathrm{CU}$ traits tend to show less aggression overall and, when they do show aggressive behavior, it tends to be largely reactive in nature. Further, many of the social-cognitive and affective differences that have been found between reactive and proactive aggression may be due to the differences in their association with $\mathrm{CU}$ traits $(\mathrm{Mu}-$ noz, Frick, Kimonis, \& Aucoin, 2008; Pardini, Lochman, \& Frick, 2003; Waschbusch, Walsh, Andrade, King, \& Carrey, 2007).

For example, Pardini et al. (2003) studied detained adolescents' (ages 11-18) responses to eight vignettes depicting peers involved in aggressive acts in various age-appropriate social contexts. Youth were asked to respond to questions asking how likely and how important various possible outcomes to the aggressive interpersonal situations were. In this ethnically diverse sample of boys and girls, CU traits were associated with responses indicating a tendency to emphasize the positive and rewarding aspects of aggression, to value the importance of being dominant in aggressive interactions, 
and to minimize the potential for punishment for being aggressive. All of these social cognitive factors have been associated with proactive aggression in past research (Dodge \& Pettit, 2003). Similarly, Munoz et al. (2008) studied 85 boys (ages 13-18) who had been detained for delinquent behavior. They reported that those who showed high rates of both reactive and proactive aggression showed lower levels of emotional reactivity to provocation, consistent with past research on adolescents who show proactive aggression (e.g., Pitts, 1997). However, this reduced reactivity to provocation was only found for those who were also high on CU traits. Finally, Frick, Cornell, Bodin, Dane, Barry, and Loney (2003) reported that a tendency to attribute hostile intent to the actions of others (i.e., a hostile attribution biase) that has been associated with reactive forms of aggression was only found in boys with conduct problems who did not show CU traits.

Frick and White (2008) provided a comprehensive review of this research on the social, cognitive, and emotional characteristics of antisocial youth with and without CU traits. First, they reviewed four studies showing that the conduct problems in youth without $\mathrm{CU}$ traits are more strongly related to dysfunctional parenting practices (see also Edens, Skopp, \& Cahill, 2008). Second, they reviewed 10 studies showing differences in how antisocial youth with and without $\mathrm{CU}$ traits process emotional stimuli, with youth high on CU traits showing deficits in the processing of negative emotional stimuli and, even more specifically, deficits to signs of fear and distress in others. Third, another 10 studies were reviewed showing distinct cognitive characteristics of antisocial youth with $\mathrm{CU}$ traits, such as being less sensitive to punishment cues, especially when a reward oriented response set is primed, showing more positive outcome expectancies in aggressive situations with peers, and being more likely to exhibit verbal deficits than other antisocial youth. Fourth, they reviewed seven studies showing that youth with CU traits have unique personality characteristics, such as showing more fearless or thrill seeking behaviors and less trait anxiety or neuroticism.

Thus, taken together, there is now a fairly substantial body of research to suggest that
CU traits designate an important subgroup of antisocial youth, that differ both in the severity and stability of their behavior but also on important emotional, cognitive, and social characteristics. These latter findings could suggest distinct etiological mechanisms leading to their antisocial behavior. As a result, like the research reviewed on the childhood and adolescentonset distinction, this research provides additional evidence supporting the concept of equifinality in understanding the development of antisocial behavior in youth.

Before discussing the different etiological mechanisms and their relationship with normal developmental processes, it is also important to note that research on $\mathrm{CU}$ traits also supports the related concept of multifinality, which recognizes that the same risk factors can have multiple developmental outcomes. Specifically, as noted previously, one characteristic of youth with $\mathrm{CU}$ traits is the presence of a fearless, thrill seeking, and behaviorally uninhibited temperament. Consistent with the importance of this temperament for the development of CU traits, Cornell and Frick (2007) reported that preschool children who were rated by their teachers as being behaviorally uninhibited were more at risk for showing problems in empathy and guilt than other children. However, they also reported that uninhibited preschoolers showed enhanced conscience development if they experienced consistent discipline and a parenting style that emphasized a strong and obedience-oriented (i.e., authoritarian) approach to parenting. These authors suggested that the underarousal exhibited by fearless children may require parents to incorporate stronger methods of socialization that bring arousal levels into an optimal range for the child to internalize parental norms for prosocial behavior (Fowles \& Kochanska, 2000; Kochanska, DeVet, Goldman, Murray, \& Putnam, 1994). Thus, the same temperamental risk factor (i.e., fearless and uninhibited) could have different outcomes (i.e., normal or deficient conscience development) depending on the type of parenting the child experiences. A similar possibility has been proposed by Patrick (in press) who suggests that the same temperament of fearlessness can lead some children to become "bold" and others "mean" depending on the presence of other temperamental traits or 
depending on the presence of certain types of socializing environments.

\section{The Interface Between Normal and Abnormal Development}

\section{Understanding developmental mechanisms}

The research reviewed in the previous section clearly suggests that there are important subgroups of antisocial youth who are at differential risk for continuing their antisocial behavior into adulthood and who show different patterns of risk factors that could suggest etiologies involving distinct developmental mechanisms. As noted previously, based on the differences in the course and correlates to antisocial behavior for youth with adolescent-onset antisocial behavior, Moffitt (2003) proposed that these children show an exaggeration of the normative process of adolescent rebellion. In contrast, children in the childhood-onset group show significant problems in adjustment across multiple developmental stages. Further, as also noted above, they also show more numerous and more severe dispositional and environmental risk factors associated with their behavior problems. However, within this group, those who show CU traits seem to show different characteristics that could suggest some differences in which developmental mechanisms may be involved in their antisocial propensities.

Specifically, the research reviewed previously suggests that children with $\mathrm{CU}$ traits designate a group of children with severe conduct problems who show a distinct temperamental style, characterized by a preference for dangerous and novel stimuli, a reward-oriented response style, and a lack of reactivity to emotional stimuli that signify distress in others. The bold and fearless temperamental style has been variously labeled as low fearfulness (Rothbart \& Bates, 1998), low behavioral inhibition (Kagan \& Snidman, 1991), low harm avoidance (Cloninger, 1987), or high daring (Lahey \& Waldman, 2003). Of importance, there have been a number of studies of normally developing children documenting both concurrent (e.g., Fowles \& Kochanska, 2000; Kochanska, Gross, Lin, \& Nichols, 2002) and predictive (Rothbart, Ahadi, \& Hershey, 1994) associations between a fearless temperament and lower scores on measures of conscience development. Further, this research has led to a number of theories to explain this link. For example, fearless children may be less likely to experience transgression-related arousal in response to behavior that has been punished by others (Kochanska, 1993; Newman, 1987). In addition, children with this temperament may be less likely to experience empathic arousal linked to the distress in others (Blair, 1999). In short, the temperamental deficits in different aspects of emotional reactivity could make it more difficult for a child to develop appropriate levels of guilt, empathy, and other dimensions of conscience that, at its extreme, could result in CU traits and severe patterns of antisocial behavior. Consistent with this theoretical model, Pardini (2006) reported that the association between fearlessness and violent delinquency was mediated by the presence of $\mathrm{CU}$ traits in a sample of adjudicated adolescents.

As noted previously, children with childhood-onset antisocial behavior but without CU traits show very different dispositional (e.g., impulsivity, low verbal intelligence, poor emotional regulation) and contextual (e.g., higher rates of family dysfunction) risk factors. Most importantly, the children in this group show high rates of anxiety (Andershed, Gustafson, Kerr \& Stattin, 2002; Frick, Lilienfeld, Ellis, Loney, \& Silverthorn, 1999; Pardini, Lochman, \& Powell, 2007), they do not typically show problems in empathy and guilt (Pardini et al., 2003), and they appear to be distressed by the effects of their behavior on others (Loney, Frick, Clemens, Ellis, \& Kerlin, 2003; Pardini et al., 2003). Thus, the antisocial behavior in this group does not seem to be easily explained by deficits in conscience development.

Given the many different types of risk factors that are found in this group, it is likely that there are a number of different causal processes that could lead to the impulsive and antisocial behavior exhibited by these youth (Frick \& Morris, 2004). For example, in this group, there is a strong association between ineffective parenting practices and their antisocial behavior. Thus, it is possible that children in this group are not socialized adequately and, as a result, do not learn to appropriately regulate their 
behavior in response to environmental contingencies (Kochanska et al., 2002). Another consistent finding for antisocial youth without CU traits is that they often have problems regulating their emotions. That is, children in this group appear to show a temperament characterized by strong emotional reactivity, a deficit in the skills needed to adequately regulate their emotional reactivity, or both (Frick \& Morris, 2004). These problems in emotional regulation can result in the child committing impulsive and unplanned aggressive and antisocial acts for which he or she may be remorseful afterward but may still have difficulty controlling in the future (Pardini et al., 2003). Such problems in regulating emotion would also explain the findings that the aggressive behavior displayed by this group tends to be confined to reactive forms of aggression (Frick, Kimonis, Dandreaux, \& Farrell, 2003; Kruh et al., 2005).

\section{Different types of deviations from normal development}

Thus, this developmental model of antisocial behavior specifies three subgroups of antisocial individuals that differ on the developmental trajectory of their antisocial behavior and on the developmental mechanisms that seem to be involved in their problem behavior. Like symptoms of most forms of psychopathology, some level of antisocial and aggressive behavior is normal in children and adolescents (Moffitt et al., 1996). Therefore, it is critical to determine the relationship between normal and abnormal patterns of antisocial behavior. The developmental models outlined above illustrate two ways that abnormal antisocial behavior can differ from normal development. Specifically, the problems in adjustment experienced by the adolescent-onset group seem to be more specific to a single developmental stage (i.e., adolescence) and result from a failure to adequately adjust to the developmental demands (e.g., separation and individuation from parents) of that stage. In contrast, both groups who show a childhood onset to their antisocial behavior show risk factors (e.g., emotional and cognitive deficits) that negatively affect development across multiple stages, albeit in different ways for the two groups.

\section{Potential gender differences}

In general, the majority of research on antisocial behavior in youth has focused on the samples of boys. Thus, the applicability of these developmental models to girls is open to question. One consistent finding is that a childhood onset to severe antisocial and aggressive behavior is much rarer in girls than in boys (Hipwell et al., 2002; Moffitt \& Capsi, 2001; White \& Piquero, 2004). However, despite the predominance of adolescent onset in antisocial girls, there is evidence that girls with severe conduct problems show poor outcomes in adulthood and show a large number of the dispositional and contextual risk factors that are more characteristic of childhood-onset antisocial behavior in boys (Frick \& Dickens, 2006).

To reconcile these findings, Silverthorn and Frick (1999) proposed a modification of the developmental model outlined above which they labeled as a delayed-onset pathway to antisocial behavior for girls. These authors proposed that antisocial and aggressive behavior in girls show the same causal mechanisms as those outlined previously for childhood-onset boys. However, their severe antisocial behavior is often delayed until adolescence coinciding with biological (e.g., hormonal changes associated with puberty) and psychosocial (e.g., less parental monitoring and supervision; greater contact with deviant peers) changes that encourage antisocial behavior in girls with predisposing vulnerabilities (e.g., CU; problems in emotional regulation). In an initial test of this theory, adjudicated adolescent girls who largely showed an adolescent onset to their antisocial behavior also showed high levels of CU traits, problems with impulse control, and a number of other social and temperamental vulnerabilities that were more similar to childhood-onset boys than to adolescent-onset boys (Silverthorn et al., 2001). Despite this initial positive finding, additional tests of this model have been more mixed (Lahey et al., 2006; McCabe et al., 2001; Moffitt \& Caspi, 2001; White \& Piquero, 2004).

As a result of these conflicting findings, the predictions made from the delayed-onset theory require further testing. Also, it is possible that, although many girls may not show the overt antisocial and aggressive behavior prior to ado- 
lescence, they may show other forms of antisocial behavior such as relational aggression. Relational aggression can be defined as behaviors that seek to harm another child's social relationships (e.g., telling lies about them, excluding them from social events) rather than physically harming the child (Crick \& Grotpeter, 1996) Several studies have shown that when girls behave aggressively, they are more likely to choose relational aggression (rather than physical or overt aggression) as a strategy for use within the peer group (Crick, 1996; Crick, Casas, \& Mosher, 1997; Crick \& Grotpeter, 1995; Lagerspetz, Björkqvist, \& Peltonen, 1988; Ostrov \& Keating, 2004). Of importance, relational aggression shares some of the same risk factors as those reviewed previously as being associated with antisocial behavior, including impulsivity (Zalecki \& Hinshaw, 2004) and CU traits (Marsee \& Frick, 2007). Therefore, it may be that girls with risk factors for antisocial behavior display relational aggressive behaviors prior to adolescence, giving them the appearance of showing an adolescent onset, if such behaviors are not assessed.

\section{Stable personality traits versus developmental transitions}

As noted previously, there is some debate as to whether antisocial personality should be defined solely by a consistent pattern of antisocial behavior or by the underlying personality traits that can lead to this pattern of behavior. In either case, there is some assumption of stability across development. In fact, many definitions of antisocial personality disorder require the presence of antisocial behavior starting in childhood or adolescence (American Psychiatric Association, 2000). Prospective studies of either clinic referred (Lahey, Loeber, Burke, \& Applegate, 2005; Robins, 1966) or community participants (Moffitt et al., 2002) have suggested that between 14 and $54 \%$ of children with severe conduct problems will show an antisocial personality disorder as adults. Further, as noted previously, children with a childhood onset to their conduct problems (Moffitt, 2003) and those with CU traits (Frick \& Dickens, 2006; Frick \& White, 2008) seem to show a more stable pattern of antisocial behavior. Thus, this research suggests that some patterns of antisocial behavior are more stable than others. Unfortunately, there are no clear guidelines to suggest what level of stability in antisocial behavior would be sufficient to warrant designation as a personality disorder. Further, even if a pattern of behavior is not highly stable, such as adolescent-onset conduct problems, it may still lead to significant impairments and warrant treatment (Dandreaux \& Frick, 2009; Moffitt et al., 1996).

The issue of stability may be even more important if one focuses on the personality traits that may lead to antisocial behavior. That is, an important consideration is whether CU traits are stable enough in children or adolescents to warrant the designation of "traits" that implies some level of continuity across development (Edens, Skeem, Cruise, \& Caufmann, 2001; Seagrave \& Grisso, 2002). There are now a number of studies showing that these traits are relatively stable from late childhood to early adolescence both when assessed by selfreport (Munoz \& Frick, 2007) or by parent report (Frick, Kimonis, et al., 2003). For example, Frick, Kimonis, et al. (2003) reported a stability estimate of .71 using an intraclass correlation coefficient across 4 years for $\mathrm{CU}$ traits in a sample of children with an average age of 10.65 at the initial assessment. This level of stability for parent report is much higher than is typically reported for parent ratings of others aspects of children's adjustment (Verhulst, Koot, \& Berden, 1990). With respect to younger children, Dadds, Frazer, Frost, and Hawes (2005) found moderate 1-year stability estimates for parent-reported $\mathrm{CU}$ traits $(r=$ $.55)$ in a community sample of Australian children who were 4 to 9 years of age. Using a more extended follow-up period (i.e., 9 years), Obradovic, Pardini, Long, and Loeber (2007) reported relatively high rates of stability for parent $(r=.50)$ but modest levels of stability for teacher ratings $(r=.27)$ ratings of $\mathrm{CU}$ traits for boys between the ages of 8 and 16. Blonigen, Hicks, Kruger, Patrick, and Iacono (2006) reported that CU traits were relatively stable $(r=.60)$ from late adolescence (age 17) into early adulthood (age 24). Further, Loney, Taylor, Butler, and Iacono (2007) reported that $\mathrm{CU}$ traits in adolescence (ages 16- 
18) were significantly stable (intraclass correlation coefficient $=.40$ ) over a 6 -year follow-up period. Finally, two studies have shown that measures of CU traits assessed prior to adolescence were significantly associated with similar measures in adulthood, even after controlling for other childhood risk factors (Burke, Loeber, \& Lahey, 2007; Lynam, Caspi, Moffitt, Loeber, $\&$ Stouthamer-Loeber, 2007).

Based on these findings, the stability of CU ratings across development appears to be better or equivalent to other trait indices across childhood to adolescence and early adulthood. However, there is no agreed on metric regarding what level of stability would warrant the classification of a "stable trait." Critically, even reasonably high levels of stability would not imply that $\mathrm{CU}$ traits are unchangeable. For example, Frick, Kimonis, et al. (2003) reported that, despite the high level of stability in these traits across their 4-year study period, there were a significant number of youth who decreased in their level of CU traits over the course of the study (for a similar pattern of change over a longer period of development, see also Lynam et al., 2007). Further, this decrease in the level of CU traits was related to the level of conduct problems displayed by the child, the socioeconomic status of the child's parents, and the quality of parenting the child received. Thus, CU traits do appear to be at least somewhat malleable and changes in their level across development seem to be influenced by factors in the child's psychosocial environment.

\section{The Importance of Multiple Levels of Analysis}

From the review provided above, it is clear that subgroups of antisocial youth differ in a number of important ways behaviorally. That is, they can differ in their timing of onset, the stability of their behavior, and the level and type of aggression that is displayed. Further, we have also noted several ways that these subgroups differ in their emotional, cognitive, social, and interpersonal functioning. Understanding differences on each of these levels provides important information for charting the varied mechanisms (e.g., deficits in conscience; poor emotional regulation) that may be involved in the development of antisocial traits. In recent years, there have been substantial increases in the number of studies exploring biological vulnerabilities to antisocial behavior (Raine \& Yang, 2006). In this section, we provide a selective review of genetic and brain imaging (focusing on functional magnetic resonance imaging [fMRI]) studies with antisocial individuals and, in particular, reviewing several areas of research that could advance our understanding of the different developmental pathways to antisocial behavior.

\section{Behavioral genetic studies}

There have been a large number of studies showing moderate heritability and nonshared environmental influence, as well as modest shared environmental influence on antisocial behavior (e.g., Mason \& Frick, 1994; Rhee \& Waldman, 2002). In other words, individual differences in susceptibility to antisocial behavior have both a heritable and environmental component. In recent years, there have been several lines of research that have attempted to go beyond this basic partitioning of genetic and environmental influences to antisocial behavior that could be especially important for understanding the different developmental pathways that may lead to severe patterns of antisocial behavior.

First, twin and adoption studies have demonstrated several important types of gene-environment correlations and gene-environment interactions. For example, risk factors that have been traditionally conceptualized as environmental (e.g., parenting reactions) may actually be evoked partly by the heritable temperamental features of the child (gene-environment correlation; Larsson, Viding, Rijsdijk, \& Plomin, 2008). Further, genetically influenced individual differences in the sensitivity to environmental risk factors such as maltreatment (gene-environment interaction) are also important in explaining variance in antisocial behavior. Specifically, research has suggested that genes regulating serotonergic neurotransmission, in particular monoamine oxidase A (MAOA), are important for explaining individual differences in antisocial behavior (Buckholtz \& Meyer-Lindenberg, 2008). However, the genetic vulnerability to antisocial behavior conferred by the MAOA 
low-activity allele $(M A O A-L)$ may only become evident in the presence of an environmental trigger, such as maltreatment (Caspi et al., 2002; Kim-Cohen et al., 2006).

Second, and more directly related to the different developmental pathways to antisocial behavior, several studies have begun studying differences in the heritability of antisocial behavior across subtypes. For example, Taylor, Iacono, and McGue (2000) reported greater genetic influence for childhood-onset delinquency, compared to adolescence-onset delinquency. A recent study by Silberg, Rutter, Tracy, Maes, and Eaves (2007) extended these findings with a larger sample of twins. They reported that a single genetic factor was important in influencing antisocial behavior that started in childhood and was persistent into adulthood. They also found that there were adolescent-onset shared environmental factors that were not influencing individual differences in antisocial behavior before adolescence. Finally, they reported a transient genetic effect at puberty and argued that this finding is consistent with a notion of genetically mediated influence on the timing of puberty affecting the expression of genetic differences in antisocial outcomes.

Directly related to the model of the CU traits differentiating subtypes within the childhoodonset group, antisocial behavior in children with CU traits has been found to be under strong genetic influence (heritability of .81) with little influence of shared environment (Viding, Blair, Moffitt, \& Plomin, 2005). In contrast, antisocial behavior in children without elevated levels of CU shows more modest genetic influence (heritability of .30) and substantial environmental influence (shared environmental influence $=.34$, nonshared environmental influence $=.26$ ). It was important that the differences in heritability could not be attributed to differences in the severity of conduct problems in this sample of 7-year-old twins. These findings were replicated when the children were 9 years old, and this latter study also demonstrated that the difference in heritability magnitude holds even after hyperactivity scores of the children were controlled (Viding, Jones, Frick, Moffitt, \& Plomin, 2008).

Thus, these behavioral genetic studies provide strong support for differences in the etiology for the different patterns of antisocial be- havior (childhood vs. adolescence onset; CU vs. non-CU), again supporting the importance of recognizing equifinality in causal models. Further, these findings are also consistent with some of the findings on behavioral, cognitive, affective, and social correlates reported previously. For example, the finding of persistent genetic influences being associated with childhood-onset antisocial behavior and new environmental influences coming to play in adolescence is consistent with the emphasis on biological and temperamental vulnerabilities for the early starters and greater emphasis on social causes for the adolescent-onset group. The finding of differences in etiological factors for antisocial behavior in children high and low on CU traits also is consistent with previous findings. For example, stronger environmental influences on antisocial behavior in children who are low on $\mathrm{CU}$ traits support those studies reviewed previously showing that parenting factors were more strongly associated with conduct problems in these children (Frick \& White, 2008).

Third, although no molecular genetic studies have directly compared different subtypes of children with conduct problems, some imaging studies have suggested that the MAOA-L risk polymorphism may relate specifically to children who show primarily impulsive and reactive types of conduct problems (for a review, see Buckholtz \& Meyer-Lindenberg, 2008). Buckholtz and Meyer-Lindenberg (2008) propose that MAOA- $L$ causes an ontogentic excess of serotonin and influences the brain's affective circuitry in a way that amplifies the effects of environmental risk, such as maltreatment. It is interesting to note that some studies have reported an increased vulnerability to antisocial behavior in the presence of the MAOA high (as opposed to low) activity allele (e.g., Manuck et al., 2000). Thus, it is possible that different alleles of the same gene may predispose to different types of conduct problems by having opposite effects on the affective lability of an individual. This would be consistent with our developmental model specifying different patterns of emotional responding across subgroups of antisocial youth. However, this possibility is highly speculative at present. As for any psychiatric outcome, the genetic influences on any 
subtype of conduct problems will not be limited to a single candidate gene. However, these findings also nicely illustrate the concept of multifinality. That is, it is unlikely that specific genes that increase the likelihood for antisocial behavior would conform to diagnostic boundaries. For example, different levels of MAOA activity have been linked to a wide range of psychiatric disorders such as depression, autism, bipolar disorder, and alcoholism (Cicchetti, Rogosch, \& Sturge-Apple, 2007; Rende \& Waldman, 2006; Shin, Chen, \& Ridd, 1999). The multifinality of outcomes suggests that any genetic risk conferred by $M A O A-L$ is likely to be moderated by both distinct environmental risk factors and other genes, as already outlined above.

Fourth, twin studies have not only begun to compare genetic and environmental influences in subgroups of antisocial youth, they have also begun to explore whether antisocial behavior, CU traits, and other related traits (e.g., substance abuse) co-occur because of common genetic and/or environmental factors (Krueger et al., 2002; Taylor, Loney, Bobadilla, Iacono, \& McGue, 2003; Viding et al., 2007). In much the same way as a comparison of identical and fraternal twins enables the partitioning of variance into genetic, shared, and nonshared environmental components, the twin design can also be used to partition covariance between traits into different etiological components. Such multivariate behavioral genetic analyses are ideal for investigating different phenotypic manifestations of shared genetic or environmental risk. In general, these types of analyses have suggested that the overlap among antisocial behavior and other externalizing symptoms or personality traits (e.g., CU) has a substantial genetic component (e.g., Viding et al., 2007). In addition, these studies have found that the nonshared environmental factors (i.e., those environmental risk factors that are not shared by two family members) are often phenotype specific. Such findings suggest that nonshared, phenotype specific, environmental risk factors are critical for differentiating the eventual behavioral outcome, even if the same genetic risk factors are important for two different behavioral patterns. It is also possible that some differentiation of behavioral outcome is be- cause of those risk genes that are not common between two distinct outcomes.

Fifth, behavior genetic studies have begun to address the issue of whether severe antisocial behavior is better thought of as being on a continuum with normal behavior or whether it is better considered a qualitatively distinct taxon (Beauchaine, 2003; Vasey, Kotov, Frick, \& Loney, 2005). One possibility is that common behavioral disorders are the quantitative extreme of the same genetic effects that operate throughout the distribution of the trait (Plomin, Owen, \& McGuffin, 1994). In this quantitative trait loci model, several genes (rather than a few rogue mutations) are hypothesized to act in a probabilistic manner to increase risk for the development of maladaptive behavioral outcome. Each gene is thought to account for only a miniscule proportion of variance for any risk outcome (Plomin, DeFries, McClearn, \& McGuffin, 2008). It is thus unsurprising that even when environmental risk factors increase the "penetrance" of genetic risk, the interaction between any specific gene and an environmental risk factor does not account for all of the variance in a maladaptive behavioral outcome (Caspi et al., 2002). Twin studies have generally documented similar heritability (and environmental) estimates across the continuum of conduct problem scores, as well as at the extreme trait level (e.g., Slutske et al., 1997; Viding et al., 2005, 2007). For example, Slutske et al. (1997) found that a multiple-threshold model of severe antisocial behavior fit their data well, suggesting that antisocial behavior seems to be an extreme of the normal variation in conduct problems, rather than a discrete entity. Similar heritability estimates for normal/ subclinical and extreme forms of behavior are in line with the quantitative trait loci model.

It is important to note that such a model does necessarily contradict the possibility that there may be different subgroups of antisocial youth with qualitatively different causal processes. That is, heritability and environmental estimates obtained at different cutoffs of any univariate distribution could be based on data from a heterogeneous group of individuals who could have a distinct set of genetic and environmental risk factors. In addition, there may be different normal to abnormal continua 
in terms of the relative importance of certain genes and environments for different subtypes. Thus, it is still possible that different subtypes of antisocial individuals could have distinct etiologies, even if their vulnerability profile on a single indicator (e.g., specific behavior or neurocognitive measure) is not qualitatively different from the rest of the population.

\section{fMRI Brain imaging studies}

Despite the demonstration of genetic influences on individual differences in antisocial behavior, it is important to emphasize that risk genes for antisocial behavior do not act deterministically. Instead, genes code for neurocognitive vulnerabilities that may, in turn, increase a child's risk for antisocial behavior in certain environmental contexts. For example, individual differences in several brain areas and cognitive functions associated with perception and regulation of emotions have been found to correlate with antisocial and violent behavior and could also mediate genetic influences (Davidson, Putnam, \& Larson, 2000). In particular, the orbitofrontal/ventromedial prefrontal cortex, anterior cingulate, amygdala, and interconnected regions have shown both structural and functional abnormalities in antisocial populations (Blair et al., 2005).

fMRI is a relatively new tool for studying antisocial behavior in children and, as a result, only a handful of studies exist to date. Hence, to date, there are no fMRI studies contrasting childhood-onset with adolescent-onset subtypes or antisocial youth with and without $\mathrm{CU}$ traits. Instead, published studies have either focused on an undifferentiated group of children with antisocial behavior or on the CU subtype alone. However, these studies do provide some at least speculative support for the developmental model that has been outlined in this paper. Specifically, reduced anterior cingulate responsivity to threatening emotional scenes under passive viewing conditions has been reported for antisocial youth, possibly reflecting poor emotional regulation (Stadler et al., 2007; Sterzer, Stadler, Krebs, Kleinschmidt, $\&$ Poutska, 2005). The same studies also reported amygdala hypoactivation to negative and threatening pictures for antisocial youth, but this result emerged only when anxiety scores were used as a covariate. A more recent study using an almost identical passive viewing paradigm found increased amygdala activation, partly related to comorbid anxiety, in children with antisocial behavior (Herpertz et al., 2008). These functional deficits would be consistent with some of the abnormalities in how children with $\mathrm{CU}$ traits process emotional stimuli.

In support of this possibility, two studies have directly measured CU traits and explicitly tested the hypothesis that this group would show amygdala hyporeactivity to others' distress (Jones, Laurens, Herbs, Baker, \& Viding, 2009; Marsh et al., 2008). Both studies employed an implicit emotion processing task (gender recognition) and found amygdala hyporeactivity to fearful faces in antisocial youth with CU traits compared to typically developing children and children with attention-deficit/hyperactivity disorder. Another study documented an abnormal ventromedial prefrontal cortex response to punishment in children with CU traits (Finger et al., 2008). This study employed a task in which the participants had to learn that a stimulus that used to be rewarding was subsequently associated with loss and that they should stop responding to that stimulus. This finding is consistent with previously reviewed findings showing abnormalities in how youth with CU traits respond to reward and punishment contingencies.

Thus, although much more work in this area is needed, these initial findings from brain imaging studies are promising in providing possible neurological bases to some of the cognitive and affective differences found across the different developmental pathways to antisocial behaviors, and could help in uncovering some of the neurocognitive mechanisms through which inherited predispositions can place a child at risk for the development antisocial traits (Viding \& Jones, 2008). Of importance, these promising studies demonstrate the importance of integrating findings across multiple levels of analyses. That is, the unique functional neurological deficits were documented when CU traits were used to form experimental groups and when tasks tapping the specific emotional and cognitive deficits that have 
been associated with these traits were used to test functional brain differences.

It is important to bear in mind that although our selective review focused on fMRI studies, such studies do not by any means represent the only avenue of investigation for charting neurobiological vulnerabilities that can mediate the genetic influences on antisocial behavior. For example, several studies have shown that youth with CU traits show differences in their autonomic reactivity to certain types of stimuli (Blair, 1999; Kimonis et al., 2008) and they show differences in both their resting (Loney, Butler, Lima, Counts, \& Eckel, 2006) and stress-induced (O'Leary, Loney, \& Eckel, 2007) cortisol levels. Thus, some of the genetic risk for this group of antisocial youth could be due to inherited individual differences in the functioning of their autonomic nervous system or in the reactivity of their hypothalamic-pituitary-adrenal axis as indexed by the hormone cortisol. Combining across all of these levels provides the greatest likelihood of advancing our knowledge of the different pathways to the equifinal outcome of antisocial behavior (Viding \& Frith, 2006).

\section{Implications for Prevention and Treatment}

The research on different subgroups of antisocial youth, and the developmental model that we have used to organize it, has several important applied implications. One key implication of this approach is an emphasis on prevention. As noted previously, the most aggressive youth, and the youth most likely to continue their antisocial behavior into adulthood, tend to show a childhood onset to their antisocial behavior. Further, there are a number of interventions that have proven effective in treating early emerging conduct problems, with a great decrease in their effectiveness in older children and adolescents (Eyberg, Nelson, \& Boggs, 2008). Thus, intervening early in the developmental trajectory of childhood-onset conduct problems is an important goal for preventing later serious aggression and antisocial behavior. However, even these interventions require a child to have already shown serious and impairing conduct problems, albeit at an early age. By focusing on the developmental processes that can precede even these early conduct problems, it opens the possibility of prevention programs that promote optimal development in children with certain risk factors (e.g., an fearless temperament, poor emotional regulation) even before serious behavioral problems emerge.

A second implication of the developmental approach to understanding antisocial behavior that was outlined in this paper is that interventions need to be comprehensive and target multiple risk factors. As noted throughout this paper, no gene, no temperamental risk factor, no environmental risk factor operates in isolation. Thus, it is not surprising that some of the most effective interventions for antisocial behavior involve multiple components, rather than targeting only a single risk factor (e.g., Conduct Problems Prevention Research Group, 2004).

A third implication of the developmental model is that interventions not only need to be comprehensive, but they also need to be individualized. That is, given that the causal processes leading to antisocial behavior appear to be different across subgroups, it is also quite likely that treatments will need to be different across these groups as well. For example, Hawes and Dadds (2005) reported that clinicreferred boys (ages 4 to 9) with conduct problems and CU traits were less responsive to a parenting intervention than boys with conduct problems who were low on CU traits. However, this differential effectiveness was not consistently found across all phases of the treatment. That is, children with and without CU traits seemed to respond equally well to the first part of the intervention that focused on teaching parents methods of using positive reinforcement to encourage prosocial behavior. In contrast, only the group without CU traits showed added improvement with the second part of the intervention that focused on teaching parents more effective discipline strategies. This outcome would be consistent with the rewardoriented response style that, as reviewed previously, appears to be characteristic of children with CU traits. In another study of the differential response to treatment of youth with $\mathrm{CU}$ traits, Waschbusch, Carrey, Willoughby, King, and Andrade (2007) reported that children (ages 7-12) with conduct problems and CU traits responded less well to behavior therapy 
alone than children with conduct problems without CU traits. However, these differences largely disappeared when stimulant medication was added to the behavior therapy, although the children with $\mathrm{CU}$ traits were still less likely to score in the normative range than those without these traits.

These findings support the contention that interventions may be more effective if they are specifically tailored to the unique needs of children within the different developmental pathways. This focus on a comprehensive and individualized approach to treatment may be particularly important for enhancing the effectiveness of existing treatments for older children and adolescents who show severe antisocial and delinquent behavior. For example, a study group commissioned by the Office of Juvenile Justice and Delinquency Prevention of the United States Department of Justice reviewed four juvenile justice programs that provided individualized and comprehensive services to adjudicated youth who were under the age of 13 (Burns et al., 2003). This summary outlined several features of such comprehensive models that appeared critical to their success. One critical feature is that there was a system for ensuring that an array of mental health, medical, child welfare, and educational services were available to adjudicated youth. In addition, there was a system for providing a comprehensive assessment to determine the specific needs of the adjudicated youth and a strong casemanagement system for ensuring that services were provided in an integrated and coherent manner. Similar models of comprehensive and individualized interventions have proven to be effective for older youth with severe antisocial behavior (Henggeler, Schoenwald, Borduin, Rowland, \& Cunningham, 1998).

Research on the various developmental pathways to antisocial behavior could be quite important for guiding these comprehensive and individualized approaches to treatment. That is, knowledge of the different developmental processes that may be operating in the various subgroups of antisocial youth could help in determining the most effective combination of services for an individual child (Frick, 2006). For example, interventions that focus on enhancing identity development in adolescents and increasing contact with prosocial peers, such as mentoring programs (Grossman \& Tierney, 1998) or programs that provide structured afterschool activities (Mahoney \& Stattin, 2000), may be particularly effective for youth within the adolescent-onset pathway. In contrast, interventions that focus on anger control may be more effective for children within the childhood-onset pathway who do not exhibit CU traits but who often show problems with emotional regulation (Larson \& Lochman, 2003). Further, interventions that intervene early in the parent-child relationship to teach parents ways to foster empathic concern in their young child or that help the child develop cognitive perspective taking skills may be more effective for children with $\mathrm{CU}$ traits (Chi-Ming, Greenberg, \& Walls, 2003). Later in development, intervening in ways that emphasize the reward-oriented response style of this group and attempt to motivate children through appealing to their self-interest, rather than through interventions that solely focus on punishment-oriented strategies, may be more effective for this group of youth (Frick, 2006).

An important note of caution relates to the behavioral genetic research reviewed above. That is, such research could lead some to consider gene therapy for antisocial behavior. Genes that have variants that are common in the population are likely to have multiple functions, some of which are desirable, others not. For example, the genetic variants that increase the probability of $\mathrm{CU}$ traits may also be protective against excessive anxiety. When this information is combined with the fact that genes interact in complex systems, as well as with environmental risk factors, it quickly becomes evident that removing the effects of one gene via gene therapy is unlikely to be effective (Nuffield Council on Bioethics, 2002).

This does not mean that genotype information is irrelevant to prevention and treatment. For example, demonstrating that there are genetically heterogeneous subtypes of childhoodonset antisocial behavior suggests the possibility of subtype-specific risk gene variants that index vulnerability for specific neurocognitive deficits. An early knowledge of such risk genes, particularly in the context of certain 
environmental factors, could also be used to guide prevention efforts prior to the emergence of severe conduct problems.

\section{Summary and Conclusions}

In this paper, we have outlined a developmental psychopathology framework for understanding the etiology of severe patterns of antisocial behavior or antisocial personality. In this framework, we outline three important pathways through which children and adolescents can develop severe antisocial behaviors. Unlike past attempts to define important subgroups of antisocial individuals, this approach does not rely solely on differences in the types of behaviors, timing of onset of behaviors, the stability of behaviors, or personality traits. Instead, an emphasis is placed on the developmental processes that may place a child at risk for acting in an antisocial and aggressive manner. Specifically, the model defines a group of youth whose antisocial behavior begins in adolescence and who seem to be showing an exaggeration of normal adolescent rebellion. Further, the model defines two groups of youth whose antisocial behavior begins prior to adolescence and who seem to show problems in adjustment across multiple developmental stages. One group is characterized by the presence of CU traits that seem related to a temperamental deficit in how they process emotional stimuli and respond to punishment cues that interfere with the normal development of empathy, guilt, and other aspects of conscience. The second group of early-onset antisocial youths show problems more related to cognitive deficits and ineffective socialization that lead to problems in the normal development of behavioral and emotional regulation.

In outlining these distinct pathways to antisocial behavior, we have tried to illustrate some key concepts from developmental psychopathology. First, we have used these pathways to illustrate the concepts of equifinality and multifinality, by showing how severe patterns of antisocial behavior can result from very different causal processes (i.e., equifinality) and how the same risk factors can lead to many different outcomes (i.e., multifinality). Second, we have illustrated how understanding the interface between normal and abnormal development is crucial for understanding the causes of antisocial behavior. That is, each pattern of antisocial behavior involves somewhat unique developmental processes and they each deviate from normative patterns of antisocial behavior in different ways. Third, we have used this model to show how using multiple levels of analyses can advance causal theories. Specifically, children in all three pathways show unique behavioral, social, emotional, cognitive, and neurological correlates that, when combined, provide an integrated causal theory that is not possible when research is restricted to any single level of analysis. Fourth, and potentially most importantly, we have highlighted how this development model can be used to enhance existing interventions for antisocial individuals, particularly by highlighting avenues for early intervention and by guiding comprehensive and individualized approaches to treatment.

Thus, we think that developmental models such as the one we have outlined in this paper need to guide etiological theories of conduct problems, aggression, and antisocial behavior. Further, this body research points the way to several potentially important directions for future research. First, a key aspect to the developmental models outlined in this manuscript is the different temperaments that may place a child at risk for showing severe antisocial and aggressive behavior. However, the vast majority of research has focused on studying the temperamental characteristics of children and adolescents who already show problem behavior. As a result, it will be critical for future research to study children with the hypothesized temperamental risk factors (e.g., low levels of fearfulness; high levels of emotional reactivity) early in development to see if the temperamental risk factors predict later conduct problems and, even more importantly, predict the specific developmental mechanisms (e.g., lack of guilt and empathy; poorly regulated emotions) that are proposed to underlie the conduct problems across the different causal pathways. Such prospective research is not only important for providing strong tests of the predictive utility of the developmental model but also could help to uncover protective factors that may reduce the 
likelihood that a child with a temperamental risk factor will show severe behavior problems. A better understanding of protective factors could be quite helpful for guiding future prevention programs. Second, we have outlined the potential importance of studying the different pathways at many different levels of analyses (e.g., behavioral, affective/cognitive, neurological). Unfortunately, only very few studies have tested predictions made by this developmental model on the neurological level, which is likely because of the type of expertise needed to conduct such studies and the great expense involved in conducting such research. However, the promising findings from the neuroimaging studies that have been conducted to

\section{References}

American Psychiatric Association. (1980). The diagnostic and statistical manual of mental disorders (3rd ed.). Washington, DC: Author.

American Psychiatric Association. (1987). The diagnostic and statistical manual of mental disorders (3rd ed., rev.). Washington, DC: Author.

American Psychiatric Association. (2000). The diagnostic and statistical manual of mental disorders (4th ed., text revision). Washington, DC: Author.

Aguilar, B., Sroufe, A., Egeland, B., \& Carlson, E. (2000). Distinguishing the early-onset/persistent and adolescence-onset antisocial behavior types: From birth to 16 years. Development and Psychopathology, 12, 109-132.

Andershed, H., Gustafson, S. B., Kerr, M., \& Stattin, H. (2002). The usefulness of self-reported psychopathylike traits in the study of antisocial behaviour among non-referred adolescents. European Journal of Personality, 16, 383-402.

Beauchaine, T. P. (2003). Taxometrics and developmental psychopathology. Development and Psychopathology, 15, 501-527.

Binder, A. (1987). An historical and theoretical introduction. In H. C. Quay (Ed.), Handbook of juvenile delinquency (pp. 1-33). New York: Wiley.

Blair, R. J. R. (1999) Responsiveness to distress cues in the child with psychopathic tendencies. Personality and Individual Differences, 27, 135-145.

Blair, R. J. R., Mitchell, D., \& Blair, K. (2005). The psychopath: Emotion and the brain. Malden, MA: Blackwell.

Blonigen, D. M., Hicks, B. M., Kruger, R. F., Patrick, C. P., $\&$ Iacono, W. G. (2006). Continuity and change in psychopathic traits as measured via normal-range personality: A longitudinal-biometric study. Journal of Abnormal Psychology, 115, 85-95.

Brezina, T., \& Piquero, A. R. (2007). Moral beliefs, isolation from peers, and abstention from delinquency. Deviant Behavior, 28, 433-465.

Broidy, L. M., Nagin, D. S., Tremblay, R. E., Bates, J. E., Brame, B. U, Dodge, K. A., et al. (2003). Developmental trajectories of childhood disruptive behaviors date clearly illustrate the great potential of future studies in this area. Third, and potentially most important, very few intervention studies have used this developmental model to tailor their interventions to the unique needs of antisocial youths in the different causal pathways. In this paper, we have made some educated hypotheses as to what types of interventions may be most effective for the different groups of antisocial youth. However, these hypotheses remain largely untested. Such tests should be a critical goal for future research, given that the few existing studies clearly suggest that youth in all three pathways can respond to interventions, albeit to different ones. and adolescent delinquency: A six-site, cross-national study. Developmental Psychology, 39, 222-245.

Buckholtz, J. W., \& Meyer-Lindenberg, A. (2008). MAOA and the neurogenetic architecture of human aggression. Trends in Neurosciences, 31, 120-129.

Burke, J. D., Loeber, R., \& Lahey, B. B. (2007). Adolescent conduct disorder and interpersonal callousness as predictors of psychopathy in young adults. Journal of Clinical Child and Adolescent Psychology, 36, 334-346.

Burns, B., Howell, J. C., Wiig, J. K., Augimeri, L. K., Welsh, B. C., Loeber, R., et al. (2003). Treatment, services, and intervention programs for child delinquents. Office of Juvenile Justice and Delinquency Child Delinquency Bulletin Series, March, 1-15.

Card, N. A., \& Little, T. D. (2006). Proactive and reactive aggression in childhood and adolescence: A meta-analysis of differential relations with psychosocial adjustment. International Journal of Behavioral Development, 30, 466-480.

Caspi, A., McClay, J., Moffitt, T., Mill, J., Martin, J., Craig, I. W., et al. (2002). Role of genotype in the cycle of violence in maltreated children. Science, 297, 851-854.

Chi-Ming, K., Greenberg, M. T., \& Walls, C. T. (2003). Examining the role of implementation quality in schoolbased prevention using the PATH curriculum. Prevention Science, 4, 55-63.

Cicchetti, D., \& Rogosch, F. A. (1996). Equifinality and multifinality in developmental psychopathology. Development and Psychopathology, 8, 597-600.

Cicchetti, D., Rogosch, F. A., \& Sturge-Apple, M. L. (2007). Interactions of child maltreatment and serotonin transporter and monoamine oxidase A polymorphisms: Depressive symptomatology among adolescents from low socioeconomic status backgrounds. Development and Psychopathology, 19, 1161-1180.

Cleckley (1976). The mask of sanity. St. Louis, MO: Mosby.

Cloninger, C. R. (1987). A systematic method for clinical description and classification of personality variants. Archives of General Psychiatry, 44, 573-588.

Conduct Problems Prevention Research Group. (2004). The effects of the Fast Track Program on serious problem 
outcome at the end of elementary school. Journal of Clinical Child and Adolescent Psychology, 33, 650 661.

Cornell, A. H., \& Frick, P. J. (2007). The moderating effects of parenting styles in the association between behavioral inhibition and parent-reported guilt and empathy in preschool children. Journal of Clinical Child and Adolescent Psychology, 36, 305-318.

Crick, N. R. (1996). The role of overt aggression, relational aggression, and prosocial behavior in the prediction of children's future social adjustment. Child Development, 67, 2317-2327.

Crick, N. R., Casas, J. F., \& Mosher, M. (1997). Relational and overt aggression in preschool. Developmental Psychology, 33, 579-588.

Crick, N. R., \& Grotpeter, J. K. (1995). Relational aggression, gender, and social-psychological adjustment. Child Development, 66, 710-722.

Dadds, M. R., Fraser, J., Frost, A., \& Hawes, D. (2005). Disentangling the underlying dimensions of psychopathy and conduct problems in childhood: A community study. Journal of Consulting and Clinical Psychology, 73, 400-410.

Dandreaux, D. M., \& Frick, P. J. (2009). Developmental pathways to conduct problems: A further test of the childhood and adolescent-onset distinction. Journal of Abnormal Child Psychology, 37, 375-385.

Davidson, R. J., Putnam, K. M., \& Larson, C. L. (2000). Dysfunction in the neural circuitry of emotion regulation: A possible prelude to violence. Science, 289, 591594.

Dodge, K. A., \& Pettit, G. S. (2003). A biopsychosocial model of the development of chronic conduct problems in adolescence. Developmental Psychology, 39, 349371.

Edens, J. F., Campbell, J. S., \& Weir, J. M. (2007). Youth psychopathy and criminal recidivism: A meta-analysis of the psychopathy checklist measures. Law and Human Behavior, 31, 53-75.

Edens, J. F., Skeem, J. L., Cruise, K. R., \& Cauffman, E. (2001). Assessment of "juvenile psychopathy" and its association with violence: A critical review. Behavioral Sciences and the Law, 19, 53-80.

Edens, J. F., Skopp, N. A., \& Cahill, M. A. (2008). Psychopathic features moderate the relationship between harsh and inconsistent parental discipline and adolescent antisocial behavior. Journal of Clinical Child and Adolescent Psychology, 37, 472-476.

Enebrink, P., Anderson, H., \& Langstrom, N. (2005). Callous-unemotional traits are associated with clinical severity in referred boys with conduct problems. Nordic Journal of Psychiatry, 59, 431-440.

Eyberg, S. M., Nelson, M. M., \& Boggs, S. R. (2008). Evidence-based psychosocial treatments for children and adolescents with disruptive behavior. Journal of Clinical Child and Adolescent Psychology, 37, 215237.

Farrington, D. P., Gallagher, B., Morley, L., St. Ledger, R. J., \& West, D. (1988). Are there any successful men from criminogenic backgrounds? Psychiatry: Journal for the Study of Interpersonal Processes, 51, 116-130.

Fergusson, D. M., Lynsky, M. T., \& Horwood, L. J. (1996). Factors associated with continuity and changes in disruptive behavior patterns between childhood and adolescence. Journal of Abnormal Child Psychology, 24, 533-553.

Finger, E. C., Marsh, A. A., Mitchell, D. G., Reid, M. E., Sims, C., Budhani, S., Kosson, D. S., et al. (2008). Ab- normal ventromedial prefrontal cortex function in children with psychopathic traits during reversal learning. Archives of General Psychiatry, 65, 586-594.

Fowles, D. C., \& Kochanska, G. (2000). Temperament as a moderator of pathways to conscience in children: The contribution of electrodermal activity. Psychophysiology, 37, 788-795.

Frick, P. J. (2006). Developmental pathways to conduct disorder. Child and Adolescent Psychiatric Clinics of North America, 15, 311-331.

Frick, P. J., Cornell, A. H., Barry, C. T., Bodin, S. D., \& Dane, H. E. (2003). Callous-unemotional traits and conduct problems in the prediction of conduct problem severity, aggression, and self-report of delinquency. Journal of Abnormal Child Psychology, 31, 457-470.

Frick, P. J., Cornell, A. H., Bodin, S. D., Dane, H. A., Barry, C. T., \& Loney, B. R. (2003). Callous-unemotional traits and developmental pathways to severe conduct problems. Developmental Psychology, 39, 246-260.

Frick, P. J., \& Dickens, C. (2006). Current perspectives on conduct disorder. Current Psychiatry Reports, 8, 59-72.

Frick, P. J., Kimonis, E. R., Dandreaux, D. M., \& Farrell, J. M. (2003). The 4-year stability of psychopathic traits in nonreferred youth. Behavioral Sciences and the Law, 21, 713-736.

Frick, P. J., Lahey, B. B., Loeber, R., Tannenbaum, L. E., Van Horn, Y., Christ, M. A. G., et al. (1993). Oppositional defiant disorder and conduct disorder: A metaanalytic review of factor analyses and cross-validation in a clinic sample. Clinical Psychology Review, 13, 319-340.

Frick, P. J., Lilienfeld, S. O., Ellis, M., Loney, B., \& Silverthorn, P. (1999). The association between anxiety and psychopathy dimensions in children. Journal of Abnormal Child Psychology, 27, 383-392.

Frick, P. J., \& Loney, B. R. (1999). Outcomes of children and adolescents with conduct disorder and oppositional defiant disorder. In H. C. Quay \& A. Hogan (Eds.), Handbook of disruptive behavior disorders (pp. 507-524). New York: Plenum Press.

Frick, P. J., \& Marsee, M. A. (2006). Psychopathy and developmental pathways to antisocial behavior in youth. In C. J. Patrick (Ed.), The handbook of psychopathy (pp. 353-375). New York: Guilford Press.

Frick, P. J., \& Morris, A. S. (2004). Temperament and developmental pathways to conduct problems. Journal of Clinical Child and Adolescent Psychology, 33, 54 68.

Frick, P. J., \& White, S. F. (2008). Research review: The importance of callous-unemotional traits for developmental models of aggressive and antisocial behavior Journal of Child Psychology and Psychiatry, 49, 359375.

Grossman, J. B., \& Tierney, J. P. (1998). Does mentoring work? An impact study of the Big Brothers/Big Sisters program. Evaluation Review, 22, 403-426.

Hare, R. D. (1993). Without conscience: The disturbing world of the psychopaths among us. New York: Guilford Press.

Hawes, D. J., \& Dadds, M. R. (2005). The treatment of conduct problems in children with callous-unemotional traits. Journal of Consulting and Clinical Psychology, 73, 737-741.

Hemphill, J. F. (2007). The Hare Psychopathy Checklist and recidivism: Methodological issues and critically evaluating empirical evidence. In H. Herve \& J. C. Yuille (Eds.), The psychopath: Theory, research, and practice (pp. 141-172). Mahwah, NJ: Erlbaum. 
Henggeler, S. W., Schoenwald, S. K., Borduin, C. M., Rowland, M. D., \& Cunningham, P. B. (1998). Multisystemic treatment of antisocial behavior in children and adolescents. New York: Guilford Press.

Herpertz, S. C., Huebner, T., Marx, I., Vloet, T. D., Fink, G. R., Stoecker, T., et al. (2008). Emotional processing in male adolescents with childhood-onset conduct disorder. Journal Child Psychology and Psychiatry, 49, 781-791.

Hipwell, A. E., Loeber, R., Stouthamer-Loeber, M., Keenan, K., White, H. R., \& Kroneman, L. (2002). Characteristics of girls with early onset disruptive and antisocial behaviour. Criminal Behavior and Mental Health, 12, 99-118.

Jones, A. P., Laurens, K. L., Herba, C., Barker, G., \& Viding, E. (2009). Amygdala hypoactivity to fearful faces in boys with conduct problems and callous-unemotional traits. American Journal of Psychiatry, 166, 95-102.

Kagan, J., \& Snidman, N. (1991). Tempermental factors in human development. American Psychologist, 46, 856862.

Kim-Cohen, J., Caspi, A., Taylor, A., Williams, B., Newcombe, R., Craig, I. W., et al. (2006). MAOA, maltreatment, and gene-environment interaction predicting children's mental health: New evidence and a metaanalysis. Molecular Psychiatry, 11, 903-913.

Kimonis, E. R., Frick, P. J., Skeem, J., Marsee, M. A., Cruise, K., Munoz, L. C., et al. (2008). Assessing callous-unemotional traits in adolescent offenders: Validation of the Inventory of Callous-Unemotional Traits. Journal of the International Association of Psychiatry and Law, 31, 241-251.

Kochanska, G. (1993). Toward a synthesis of parental socialization and child temperament in early development of conscience. Child Development, 64, 325-347.

Kochanska, G., DeVet, K., Goldman, M., Murray, K., \& Putnam, S. P. (1994). Maternal reports of conscience development and temperament in young children. Child Development, 65, 852-868.

Kochanska, G., Gross, J. N., Lin, M., \& Nichols, K. E. (2002). Guilt in young children: Development, determinants, and relations with a broader system of standards. Child Development, 73, 461-482.

Kratzer, L., \& Hodgins, S. (1999). A typology of offenders: A test of Moffitt's theory among males and females from childhood to age 30. Criminal Behaviour and Mental Health, 9, 57-73.

Krueger, R. F., Hicks, B. M., Patrick, C. J., Carlson, S. R., Iacono, W. G., \& McGue, M. (2002). Etiologic connections among substance dependence, antisocial behavior, and personality: modeling the externalizing spectrum. Journal of Abnormal Psychology, 111, 411-424.

Krug, E. G., Dahlberg, L. L., Mercy, J. A., Zwi, A. B., \& Lozano, R. (2002). World report on violence and health. Geneva: World Health Organisation.

Kruh, I. P., Frick, P. J., \& Clements, C. B. (2005). Historical and personality correlates to the violence patterns of juveniles tried as adults. Criminal Justice and Behavior, 32, 69-96.

Lacourse, E., Dupere, V., \& Loeber, R. (2008). Developmental trajectories of violence and theft. In R. Loeber, D. P. Farrington, M. Stouthamer-Loeber, \& H. R. White (Eds.), Violence and serious theft: Development and prediction from childhood to adulthood (pp. 231268). New York: Routledge.

Lagerspetz, K. M. J., Björkqvist, K., \& Peltonen, T. (1988). Is indirect aggression typical of females? Gender differ- ences in aggressiveness in 11-to 12-year-old children. Aggressive Behavior, 14, 403-414.

Lahey, B. B., \& Loeber, R. (1994). Framework for a developmental model of oppositional defiant disorder and conduct disorder. In D. K. Routh (Ed.), Disruptive behavior disorders in childhood (pp. 139-180). New York: Plenum Press.

Lahey, B. B., Loeber, R., Burke, J. D., \& Applegate, B. (2005). Predicting future antisocial personality disorder in males from a clinical assessment in childhood. Journal of Consulting and Clinical Psychology, 73, 389-399.

Lahey, B. B., Van Hulle, C. A., Waldman, I. D., Rodgers, J. L, D’Onofrio, B. M., Pedlow, S., et al. (2006). Testing descriptive hypotheses regarding sex differences in the development of conduct problems and delinquency. Journal of Abnormal Child Psychology, 34, 737-755.

Lahey, B. B., \& Waldman, I. D. (2003). A developmental propensity model of the origins of conduct problems during childhood and adolescence. In B. B. Lahey, T. E. Moffitt, \& A. Caspi (Eds.), Causes of conduct disorder and juvenile delinquency (pp. 76-117). New York: Guilford Press.

Larson, J., \& Lochman, J. E. (2003). Helping schoolchildren cope with anger. New York: Guilford Press.

Larsson, H., Viding, E., Rijsdijk, F., \& Plomin, R. (2008). Relationships between a parental negativity and childhood antisocial behavior over time: A bidirectional effect model in a longitudinal genetically informative design. Journal of Abnormal Child Psychology, 36, 633-645.

Lilienfeld, S. O., \& Marino, L. (1995). Mental disorder as a Roschian concept: A critique of Wakefield's "harmful dysfunction" analysis. Journal of Abnormal Psychology, 104, 411-420.

Leistico, A. R., Salekin, R. T., DeCoster, J., \& Rogers, R. (2008). A large-scale meta-analysis related the Hare measures of psychopathy to antisocial conduct. Law and Human Behavior, 32, 28-45.

Loeber, R., \& Farrington, D. P. (2001). The significance of child delinquency. In R. Loeber \& D. Farrington (Eds.), Child delinquents: Development, intervention, and service needs (pp. 1-24). Thousand Oaks, CA: Sage.

Loney, B. R., Butler, M. A., Lima, E. N., Counts, C. A., \& Eckel, L. A. (2006). The relation between salivary cortisol, callous-unemotional traits, and conduct problems in an adolescent non-referred sample. Journal of Child Psychology and Psychiatry, 47, 30-36.

Loney, B. R., Frick, P. J., Clements, C. B., Ellis, M. L., \& Kerlin, K. (2003). Callous-unemotional traits, impulsivity, and emotional processing in adolescents with antisocial behavior problems. Journal of Clinical Child and Adolescent Psychology, 32, 66-80.

Loney, B. R., Taylor, J., Butler, M. A., \& Iacono, W. G. (2007). Adolescent psychopathy features: 6-year stability and the prediction of externalizing symptoms during the transition to adulthood. Aggressive Behavior, 33 , 242-252.

Lykken, D. (1995). The antisocial personalities. Hillsdale, NJ: Erlbaum.

Lynam, D. R., Caspi, A., Moffitt, T. E., Loeber, R., \& Stouthamer-Loeber, M. (2007). Longitudinal evidence that psychopathy scores in early adolescence predict adult psychopathy. Journal of Abnormal Psychology, 116, 155-165.

Lynam, D. R., \& Widiger, T. A. (2001). Using the five-factor model to represent the DSM-IV personality disorders: An expert consensus approach. Journal of Abnormal Psychology, 110, 401-412. 
Mahoney, J. L., \& Stattin, H. (2000). Leisure activities and adolescent antisocial behavior: The role of structure and social context. Journal of Adolescence, 23, 113-127.

Manuck, S. B., Flory, J. D., Ferrell, R. E., Mann, J. J., \& Muldoon, M. F. (2000). A regulatory polymorphism of the monoamine oxidase: A gene may be associated with variability in aggression, impulsivity, and central nervous system serotonergic responsivity. Psychiatry Research, 95, 9-23.

Marsee, M. A., \& Frick, P. J. (2007). Exploring the cognitive and emotional correlates to proactive and reactive aggression in a sample of detained girls. Journal of Abnormal Child Psychology, 35, 969-981.

Marsh, A. A., Finger, E. C., Mitchell, D. G., Reid, M. E., Sims, C., Kosson, D. S., et al. (2008). Reduced amygdala response to fearful expressions in children and adolescents with callous-unemotional traits and disruptive behavior disorders. American Journal of Psychiatry, 165, 712-720.

Mason, D. A., \& Frick, P. J. (1994). The heritabilty of antisocial behavior: A meta-analysis of twin and adoption studies. Journal of Psychopathology and Behavioral Assessment, 16, 301-323.

McCabe, K. M., Hough, R., Wood, P. A., \& Yeh, M. (2001). Childhood and adolescent onset conduct disorder: A test of the developmental taxonomy. Journal of Abnormal Child Psychology, 29, 305-316.

Moffitt, T. E. (1993). Adolescence-limited and life-course persistent antisocial behavior: A developmental taxonomy. Psychological Review, 100, 674-701.

Moffitt, T. E. (2003). Life-course persistent and adolescence-limited antisocial behavior: A 10-year research review and research agenda. In B. B. Lahey, T. E. Moffitt, \& A. Caspi (Eds.), Causes of conduct disorder and juvenile delinquency (pp. 49-75). New York: Guilford Press.

Moffitt, T. E., \& Caspi, A. (2001). Childhood predictors differentiate life-course persistent and adolescence-limited antisocial pathways in males and females. Development and Psychopathology, 13, 355-376.

Moffitt, T. E., Caspi, A., Dickson, N., Silva, P., \& Stanton, W. (1996). Childhood-onset versus adolescent-onset antisocial conduct problems in males: Natural history from ages 3 to 18 years. Development and Psychopathology, 8, 399-424.

Moffitt, T. E., Caspi, A., Harrington, H., \& Milne, B. J. (2002). Males on the life-course-persistent and adolescence-limited antisocial pathways: Follow-up at age 26 years. Development and Psychopathology, 14, 179207.

Munoz, L. C., \& Frick, P. J. (2007). The reliability, stability, and predictive utility of the self-report version of the Antisocial Process Screening Device. Scandinavian Journal of Psychology, 48, 299-312.

Munoz, L. C., Frick, P. J., Kimonis, E. R., \& Aucoin, K. J. (2008). Types of aggression, responsiveness to provocation, and callous-unemotional traits in detained adolescents. Journal of Abnormal Child Psychology, 36, 15-28.

Newman, J. P. (1987). Reaction to punishment in extraverts and psychopaths: Implications for the impulsive behavior of disinhibited individuals. Journal of Research in Personality, 21, 464-480.

Nuffield Council on Bioethics. (2002). Genetics and human behaviour: The ethical context. London: Nuffield Council on Bioethics.

Obradović, J., Pardini, D., Long, J. D., \& Loeber, R. (2007). Measuring interpersonal callousness in boys from childhood to adolescence: An examination of longitudinal invariance and temporal stability. Journal of Clinical Child and Adolescent Psychology, 36, 276-292.

O'Leary, M. M., Loney, B. R., \& Eckel, L. A. (2007). Gender differences in the association between psychopathic personality traits and cortisol response to induced stress. Psychoneuroendocrinology, 32, 183-191.

Ostrov, J. M., \& Keating, C. F. (2004). Gender differences in preschool aggression during free play and structured interactions: An observational study. Social Development, 13, 255-275.

Pardini, D. A. (2006). The callousness pathway to severe violent delinquency. Aggressive Behavior, 32, 1-9.

Pardini, D. A., Lochman, J. E., \& Frick, P. J. (2003). Callous/unemotional traits and social-cognitive processes in adjudicated youths. Journal of the American Academy of Child \& Adolescent Psychiatry, 42, 364-371.

Pardini, D. A., Lochman, J. E., \& Powell, N. (2007). The development of callous-unemotional traits and antisocial behavior in children: Are there shared and/or unique predictors? Journal of Clinical Child and Adolescent Psychology, 36, 319-333.

Patrick, C. J. (in press). The construct of psychopathy. In D. R. Lynam \& R. T. Salekin (Eds.), Handbook of child and adolescent psychopathy. New York: Guilford Press.

Patrick, C. J. (2007). Getting to the heart of psychopathy. In H. Herves \& J. C. Yuille (Eds.), The psychopathy: Theory, research, and practice (pp. 207-252). Mahwah, NJ: Erlbaum.

Patterson, G. R. (1996). Performance models for antisocial boys. American Psychologist, 41, 432-444.

Patterson, G. R., \& Yoerger, K. (1997). A developmental model for late-onset delinquency. In D. W. Osgood (Ed.), Motivation and delinquency (pp. 119-177). Lincoln, NE: University of Nebraska Press.

Piquero, A. (2001). Testing Moffitt's neuropsychological variation hypothesis for the prediction of life-course persistent offending. Psychology, Crime, and Law, 7, 193-215.

Pitts, T. B. (1997). Reduced heart rate levels in aggressive children. In A. Raine, P. A. Brennan, D. P. Farrington, \& S. A. Mednick (Eds.), Biosocial bases of violence (pp. 317-320). New York: Plenum Press.

Plomin, R., DeFries, J., McClearn, G., \& McGuffin, P. (2008). Behavioral genetics (5th ed.). New York: Worth.

Plomin, R., Owen, M. J., \& McGuffin, P. (1994). The genetic basis of complex human behaviors. Science, 264, 1733-1739.

Porter, S., \& Woodworth, M. (2006). Psychopathy and aggression. In C. J. Patrick (Ed.), Handbook of psychopathy (pp. 481-494). New York: Guilford Press.

Raine, A., \& Yang, Y. (2006). Neural foundations to moral reasoning and antisocial behavior. Social Cognitive and Affective Neuroscience, 1, 203-213.

Raine, A., Yaralian, P. S., Reynolds, C., Venables, P. H., \& Mednick, S. A. (2002). Spatial but not verbal cognitive deficits at age 3 years in persistently antisocial individuals. Development and Psychopathology, 14, 25-44.

Rende, R., \& Waldman, I. (2006). Behavioral and molecular genetics and developmental psychopathology. In D Cicchetti \& D. Cohen (Eds.), Developmental psychopathology (Vol. 2, 2nd ed., pp. 427-464). New York: Wiley.

Rhee, S. H., \& Waldman, I. D. (2002). Genetic and environmental influences on antisocial behavior: A meta-analysis of twin and adoption studies. Psychological Bulletin, 128, 490-529.

Richters, J. E., \& Cicchetti, D. (1993). Mark Twain meets DSM-III-R: Conduct disorder, development, and the 
concept of harmful dysfunction. Development and Psychopathology, 5, 5-29.

Robins, L. N. (1966). Deviant children grown up. Baltimore, MD: Williams \& Wilkins.

Robins, L. N. (1978). Aetiological implications in studies of childhood histories related to antisocial personality. In R. D. Hare \& D. Schalling (Eds.), Psychopathic behavior: Approaches to research (pp. 255-271). Chichester: Wiley.

Rothbart, M. K., Ahadi, S. A., \& Hershey, K. (1994). Temperament and social behavior in childhood. MerrillPalmer Quarterly, 40, 21-39.

Rothbart, M. K., \& Bates, J. E. (1998). Temperament. In W. Damon \& N. Eisenberg (Eds.), Handbook of child psychology: Social, emotional, and personality development (pp. 105-176). New York: Wiley.

Salekin, R. T. (2008). Psychopathy and recidivism form mid-adolescence to young adulthood: Cumulating legal problems and limiting life opportunities. Journal of Abnormal Psychology, 117, 386-395.

Seagrave, D., \& Grisso, T. (2002). Adolescent development and the measurement of juvenile psychopathy. Law and Human Behavior, 26, 219-239.

Shin, J. C., Chen, K., \& Ridd, M. J. (1999). Monoamine oxidase: From genes to behavior. Annual Review of Neuroscience, 22, 197-217.

Silberg, J. L., Rutter, M., Tracy, K., Maes, H. H., \& Eaves, L. (2007). Etiological heterogeneity in the development of antisocial behavior: The Virginia Twin Study of Adolescent Behavioral Development and the Young Adult Follow-Up. Psychological Medicine, 37, 1193-1202.

Silverthorn, P., \& Frick, P. J. (1999). Developmental pathways to antisocial behavior: The delayed-onset pathway in girls. Development and Psychopathology, 11, 101-126.

Silverthorn, P., Frick, P. J., \& Reynolds, R. (2001). Timing of onset ad correlates of severe conduct problems in adjudicated girls and boys. Journal of Psychopathology and Behavioral Assessment, 23, 171-181.

Slutske, W. S., Heath, A. C., Dinwiddie, S. H., Madden, P. A., Bucholz, K. K., Dunne, M. P., et al. (1997). Modeling genetic and environmental influences in the etiology of conduct disorder: A study of 2,682 adult twin pairs. Journal of Abnormal Psychology, 106, 266-279.

Snyder, J., Schrepferman, L., McEachern, A., Barner, S., Johnson, K., \& Provines, J. (2008). Peer deviancy training and peer coercion: Dual processes associated with early-onset conduct problems. Child Development, 79, 252-268

Stadler, C., Sterzer, P., Schmeck, K., Krebs, A., Kleinschmidt, A., \& Poustka, F. (2007). Reduced anterior cingulate activation in aggressive children and adolescents during affective stimulation: association with temperament traits. Journal of Psychiatry Research, 41, $410-417$.

Sterzer, P., Stadler, C., Krebs, A., Kleinschmidt, A., \& Poutska, F. (2005). Abnormal neural responses to emotional visual stimuli in adolescents with conduct disorder. Biological Psychiatry, 57, 7-15.

Taylor, J., Iacono, W. G., \& McGue, M. (2000). Evidence for a genetic etiology of early-onset delinquency. Journal of Abnormal Psychology, 109, 634-643.

Taylor, J., Loney, B. R., Bobadilla, L., lacono, W. G., \& McGue, M. (2003). Genetic and environmental influ- ences on psychopathy trait dimensions in a community sample of male twins. Journal of Abnormal Child Psychology, 3, 633-645.

Vasay, M. W., Kotov, R., Frick, P. J., \& Loney, B. R. (2005). The latent structure of psychopathy in youth: A taxometric investigation. Journal of Abnormal Child Psychology, 33, 411-429.

Verhulst, F. C., Koot, H. M., \& Berden, G. F. (1990). Fouryear follow-up of an epidemiological sample. Journal of American Academy of Child \& Adolescent Psychiatry, 29, 440-448.

Viding, E., Blair, R. J. R., Moffitt, T. E., \& Plomin, R. (2005). Evidence for substantial genetic risk for psychopathy in 7-year-olds. Journal of Child Psychology and Psychiatry, 46, 592-597.

Viding, E., \& Frith, U. (2006). Genes for violence lurk in the brain. Commentary. Proceedings of the National Academy of Sciences of the United States of America, 103, 6085-6086.

Viding, E., Frick, P. J., \& Plomin, R. (2007). Aetiology of the relationship between callous-unemotional traits and conduct problems in childhood. British Journal of Psychiatry, 49, s33-s38.

Viding, E., \& Jones, A. P. (2008). Cognition to genes via the brain in the study of conduct disorder. Quarterly Journal of Experimental Psychology, 61, 171-181.

Viding, E., Jones, A. P., Frick, P. J., Moffitt, T. E., \& Plomin, R. (2008). Heritability of antisocial behaviour at nine-years: Do callous-unemotional traits matter? Developmental Science, 11, 17-22.

Wakefield, J. C. (1992). Disorder as a harmful dysfunction: A conceptual critique of DSM-III-R's definition of mental disorder. Psychological Review, 99, 232-247.

Wakefield, J. C., Pottick, K. J., \& Kirk, S. A. (2002). Should the DSM-IV diagnostic criteria for conduct disorder consider social context? American Journal of Psychiatry, 159, 380-386.

Waschbusch, D. A., Carrey, N. J., Willoughby, M. T., King, S., \& Andrade, B. F. (2007). Effects of methylphenidate and behavior modification on the social and academic behavior of children with disruptive behavior disorders The moderating role of callous/unemotional traits. Journal of Clinical Child and Adolescent Psychology, 36, 629-644.

Waschbusch, D. A., Walsh, T. M., Andrade, B .F., King, S., \& Carrey, N. J. (2007). Social problem solving, conduct problems, and callous-unemotional traits in children. Child Psychiatry and Human Development, 37, 293-305.

White, N. A., \& Piquero, A. R. (2004). A preliminary empirical test of Silverthorn and Frick's delayed-onset pathway in girls using an urban, African-American, US-based sample. Criminal Behavior and Mental Health, 14, 291-309.

Woodward, L. J., Fergusson, D. M., \& Horwood, L. J. (2002). Romantic relationships of young people with childhood and adolescent onset antisocial behavior problems. Journal of Abnormal Child Psychology, 30, 231-244.

Zalecki, C. A., \& Hinshaw, S. P. (2004). Overt and relational aggression in girls with attention deficit hyperactivity disorder. Journal of Clinical Child and Adolescent Psychology, 33, 125-137. 